\title{
Bmi1 regulates murine intestinal stem cell proliferation and self-renewal downstream of Notch
}

\author{
Erika López-Arribillaga ${ }^{1, *}$, Verónica Rodilla ${ }^{1, *}$, Luca Pellegrinet ${ }^{2}$, Jordi Guiu1 ${ }^{1}$, Mar Iglesias ${ }^{3}$, \\ Angel Carlos Roman ${ }^{4}$, Susana Gutarra ${ }^{5}$, Susana González ${ }^{6}$, Pura Muñoz-Cánoves ${ }^{5,7}$, \\ Pedro Fernández-Salguero ${ }^{4}$, Freddy Radtke ${ }^{2}$, Anna Bigas ${ }^{1, *, \ddagger}$ and Lluís Espinosa ${ }^{1, *, \neq}$
}

\begin{abstract}
Genetic data indicate that abrogation of Notch-Rbpj or Wnt- $\beta$-catenin pathways results in the loss of the intestinal stem cells (ISCs). However, whether the effect of Notch is direct or due to the aberrant differentiation of the transit-amplifying cells into post-mitotic goblet cells is unknown. To address this issue, we have generated composite tamoxifen-inducible intestine-specific genetic mouse models and analyzed the expression of intestinal differentiation markers. Importantly, we found that activation of $\beta$-catenin partially rescues the differentiation phenotype of Rbpj deletion mutants, but not the loss of the ISC compartment. Moreover, we identified Bmi1, which is expressed in the ISC and progenitor compartments, as a gene that is co-regulated by Notch and $\beta$-catenin. Loss of Bmi1 resulted in reduced proliferation in the ISC compartment accompanied by $p 16^{I N K 4 a}$ and $p 19^{A R F}$ (splice variants of Cdkn2a) accumulation, and increased differentiation to the post-mitotic goblet cell lineage that partially mimics Notch loss-of-function defects. Finally, we provide evidence that Bmi1 contributes to ISC self-renewal.
\end{abstract}

KEY WORDS: Notch, $\beta$-catenin, Intestinal stem cells, Bmi1, Self-renewal

\section{INTRODUCTION}

The intestinal epithelium constitutes an excellent system for studying stem cell function. Intestinal stem cells (ISCs) reside at the bottom of intestinal crypts, where they are maintained in a multipotent and self-renewing state. ISCs are the source of a transitamplifying compartment, which undergoes $~ 4-5$ rounds of rapid cell division (Marshman et al., 2002) before achieving the terminally differentiated state. Then, the resulting differentiated enterocytes, goblet cells and enteroendocrine cells move towards the tip of the villi in a process that takes around 2-4 days, whereas a fourth differentiated cell type, the Paneth cells, migrate downwards to the crypt base where they reside for 6-8 weeks (van der Flier et al., 2009). Long-term lineage tracing has identified Lgr5, Bmil, Tert and Hopx (Barker et al., 2007; Montgomery et al., 2011; Sangiorgi and Capecchi, 2008; Schepers et al., 2011; Takeda et al., 2011; Tian

\footnotetext{
${ }^{1}$ Program in Cancer Research, IMIM-Hospital del Mar, Barcelona 08003, Spain. ${ }^{2}$ Ecole Polytechnique Federale de Lausanne, Lausanne 1015, Switzerland.

${ }^{3}$ Department of Pathology, Hospital del Mar, Barcelona 08003, Spain. ${ }^{4}$ Department of Biochemistry and Molecular Biology, University of Extremadura, Badajoz 06071, Spain. ${ }^{5}$ Departament de Ciències Experimentals, Universitat Pompeu Fabra, Barcelona 08003, Spain. ${ }^{6}$ Stem Cell Aging Group, Centro Nacional de Investigaciones Cardiovasculares (CNIC), Madrid 28029, Spain. ${ }^{7}$ Institució Catalana de Recerca i Estudis Avançats (ICREA), Barcelona 08003, Spain. *These authors contributed equally to this work

${ }^{\ddagger}$ Authors for correspondence (abigas@imim.es; lespinosa@imim.es)
}

Received 2 January 2014; Accepted 28 October 2014 et al., 2011) as ISC markers. However, it is plausible that different levels of these markers identify specific ISC subpopulations (Itzkovitz et al., 2012).

Notch and Wnt- $\beta$-catenin pathways are essential regulators of normal stem cells in multiple tissues, including the intestine (Ireland et al., 2004; Korinek et al., 1998; Pellegrinet et al., 2011; Riccio et al., 2008), and several examples of co-regulatory crosstalk have been described (Espinosa et al., 2003; Estrach et al., 2006; Hayward et al., 2005; Kwon et al., 2011; Rodilla et al., 2009). Notch signaling is activated by specific ligands that are present in neighboring cells, whereas $\beta$-catenin activation relies on the presence of soluble Wnt ligands (reviewed in Bigas et al., 2013). By using lineage-tracing analysis, it has recently been proven that Notch1 and Notch2 are specifically expressed (Fre et al., 2011) and required (Riccio et al., 2008) to maintain homeostasis in the intestinal crypt, with the Paneth cells being responsible for producing Wnt and Notch signals (Sato et al., 2011). Complete inhibition of Notch signaling in the intestinal epithelium results in the loss of the proliferative crypt compartment and the loss of the conversion of crypt progenitors into the post-mitotic secretory lineages (van Es et al., 2005), partially overlapping with the phenotype that is obtained after deletion of the Notch target gene Hes1 (Jensen et al., 2000). The molecular basis for the differentiation-associated defects is the overexpression of Math1, a master regulator of the absorptive intestinal lineage, which is repressed by Hes1. Nevertheless, genetic inactivation of Hes 1 or knockout (KO) of Hes 1, Hes 3 and Hes 5 simultaneously in the adult mouse intestine leads to reduced cell proliferation and increased secretory cell formation but does not affect ISC integrity (Ueo et al., 2012).

Bmil is a member of the Polycomb group of transcriptional repressors, the function of which in the intestine is unknown. Bmil is an essential regulator of hematopoietic, neural and lung epithelial stem cells, mainly through repression of the cell cycle regulators p $16^{\mathrm{INK} 4 \mathrm{a}}$ and $\mathrm{p} 19^{\mathrm{ARF}}$ (splice variants encoded by $C d k n 2 a-$ Mouse Genome Informatics) (Bruggeman et al., 2005; Molofsky et al., 2005; Oguro et al., 2006; Zacharek et al., 2011). Deletion of both $p 16^{I N K 4 a}$ and $p 19^{A R F}$ genes substantially restores the self-renewal capacity of $\mathrm{Bmi1}^{-/-}$hematopoietic stem cells (HSCs) (Oguro et al., 2006), whereas increased $\mathrm{p} 16^{\mathrm{INK} 4 \mathrm{a}}$ levels that are found in old mice induce an aging-associated decrease in HSC self-renewal (Janzen et al., 2006). Interestingly, Bmil null mice do not show any evident developmental defect, but they die prematurely (around 2-3 months), which is associated with a progressive decrease in the number of hematopoietic cells and with different neurological abnormalities. In the intestine, Bmil was initially detected in label-retaining stem cells located at the +4 position from the bottom of the crypt. This labelretaining feature might indicate a quiescent nature or the capacity to asymmetrically segregate DNA strands (Li and Clevers, 2010; Potten et al., 2002). However, we and others (Munoz et al., 2012) 
demonstrate that Bmil expression is unrestricted throughout the crypt compartment, similar to that of other proposed stem cell markers, such as Hopx and Tert.

We find here that Bmil is a downstream effector of Notch in the ISC and progenitor compartment and that Bmil is involved in ISC self-renewal.

\section{RESULTS}

Notch and Wnt pathways are simultaneously required to maintain the intestinal stem cell compartment in vivo

We first investigated the relative contribution of Notch to the ISC compartment using a combination of gain- and loss-of-function (GOF and LOF, respectively) mutants that had been previously developed. Specifically, we used a tamoxifen-inducible Cre recombinase driven by the villin promoter (Villin-Cre ${ }^{\text {ER-T2}}$ ) to conditionally delete $R b p j$ in the intestinal epithelium, which we combined with the active form of $\beta$-catenin $\left(C t n n b 1^{\text {lox(ex3)}}\right)$. We have previously demonstrated that genetic depletion of Notch signaling results in the complete loss of ISC markers and the intestinal stem cell function (Pellegrinet et al., 2011; Riccio et al., 2008). We have now confirmed this Notchdependent ISC phenotype and found that it was not rescued by ectopic activation of the $\beta$-catenin pathway using $R b p j^{\text {lox }} C_{C t n n b 1^{\text {lox(ex3) }} \text { mice }}$ (Fig. 1A,B; supplementary material Fig. S1). Consequently, all single and double mutants died around day 5-6 after the first tamoxifen injection. As a control, constitutive activation of $\beta$-catenin alone led to the expansion of the undifferentiated crypt compartment, which was accompanied by ectopic expression of $\mathrm{Olfm} 4, \mathrm{Lgr} 5$ and Ascl2. Immunohistochemistry (IHC) analysis of these mice further confirmed that post-mitotic goblet cells (Fig. 1C) accumulate in the intestinal crypts of Rbpj-depleted mice, which was associated with a profound reduction of the proliferative compartment, as shown by the small number of Ki67-positive cells. Interestingly, in the intestinal crypts of the composite $\mathrm{Rbpj}^{\text {lox}} ; \mathrm{Ctnnbl}^{\mathrm{lox}(\mathrm{ex} 3)}$ mutants, both the differentiation to goblet cells imposed by Rbpj (Notch) LOF, and
A
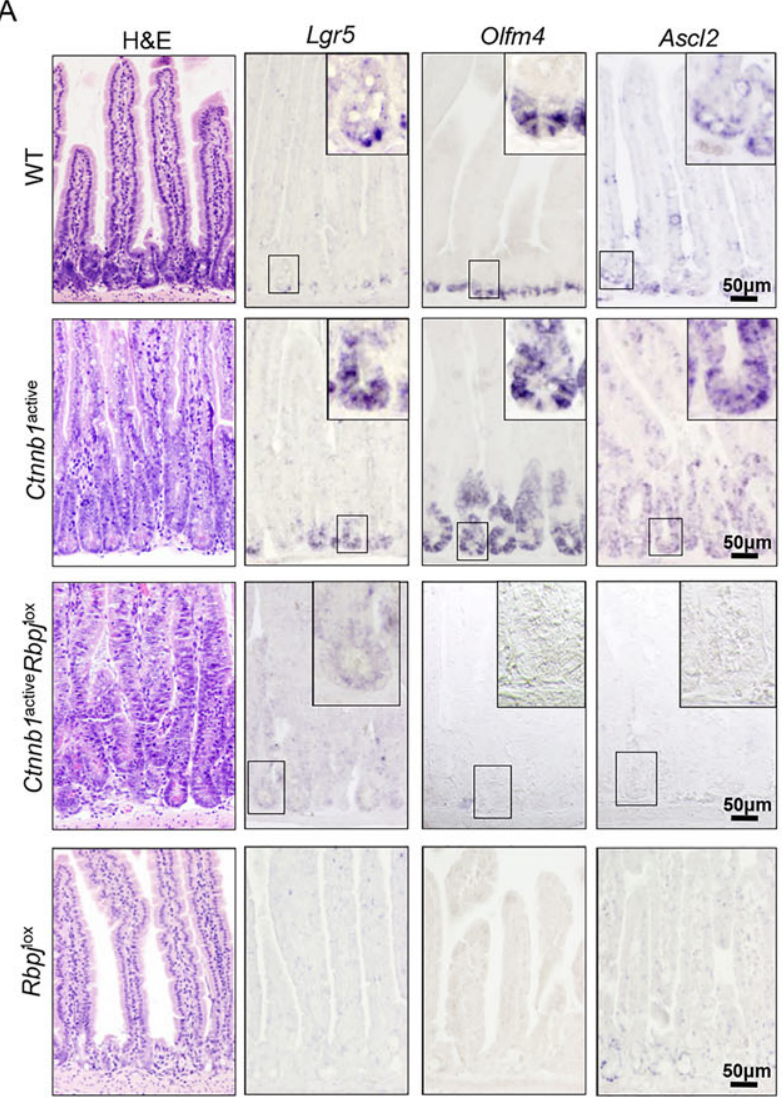

B
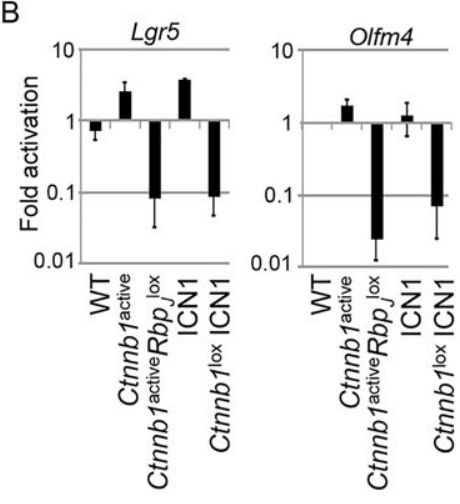

C

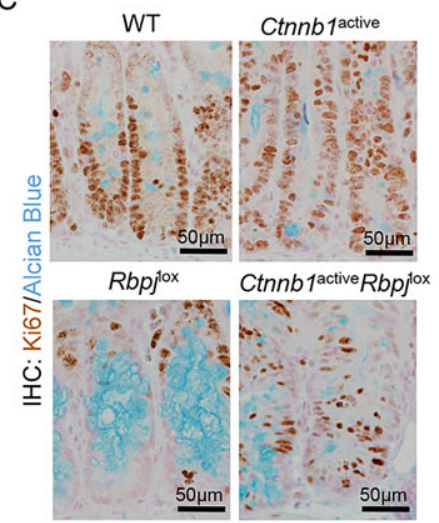

D

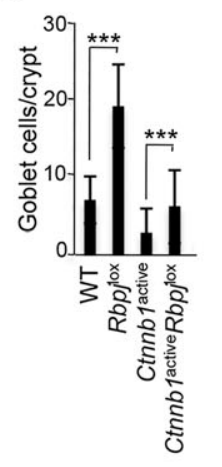

Fig. 1. Notch and $\beta$-catenin are both required for maintaining intestinal homeostasis in vivo. (A) In situ hybridization (ISH) of different stem cell markers on intestinal sections from the indicated mouse genotypes in the Villin-Cre ${ }^{E R-T 2}$ background, 4 days after treatment with tamoxifen. Insets show enlarged images of the boxed areas. (B) Quantification of the expression levels of the indicated genes by qRT-PCR analysis from isolated intestinal crypts, normalized against Villin expression. (C) Anti-Ki67 IHC and Alcian Blue staining of goblet cells on intestinal crypts of the indicated genotypes. $(D, E)$ Quantification of the number of goblet (D) and Ki67-positive cells (E) per crypt unit in more than 40 crypts counted per genotype. For Alcian Blue staining, nuclei were counterstained with Fast Red dye. Ctnnb $1^{\text {active }}$ corresponds to the $\beta$-catenin GOF mutant $C t n n b 1^{\text {lox (ex } 3)}$ and $R b p j^{\text {lox }}$ to the Notch LOF mutant. ICN1 corresponds to the inducible Notch1 GOF mutant ICN $1^{\text {LSL. In }}$ C-E, error bars represent the s.d., and statistical significance was determined using Student's $t$-test. ${ }^{*} P<0.05,{ }^{* *} P<0.01$ and ${ }^{* * *} P<0.001$. H\&E, hematoxylin and eosin staining. 
the reduction in the number of proliferating ISCs and progenitor cells were significantly rescued, leading to values comparable to those of the wild-type (WT) intestine, although reduced compared with the single $\beta$-catenin GOF (Fig. 1C-E).

These results indicate that $\beta$-catenin activation partially compensates the effect of Rbpj (Notch) LOF in goblet cell differentiation without rescuing the loss of the ISC compartment.

\section{Transcriptional activation of the Bmi1 gene is downstream of Notch and $\beta$-catenin}

To better understand the requirement for Notch in the ISC compartment, we explored a previously identified transcriptional gene signature that is simultaneously dependent on Notch and $\beta$-catenin in colorectal cancer cells (Rodilla et al., 2009). The ISCrelated gene $P C G F 4 / B m i l$ was included in this signature as it was downregulated following $\beta$-catenin or Notch inhibition, but failed to be induced by active Notch1 (intracellular fragment of Notch1, ICN1) in the absence of $\beta$-catenin signaling. By contrast, the canonical Notch target gene Hesl was found to be strictly dependent on ICN1 in intestinal cancer cells (Fig. 2A). Using the Genomatix software, we identified several adjacent TCF- and Rbpjbinding consensus sequences in the regulatory region of the murine Bmil gene that were functionally validated in purified murine crypt cells by sequential chromatin immunoprecipitation (ChIP) assay. In particular, the recruitment of Notch and $\beta$-catenin proteins was detected in a predicted region close to the transcriptional start site that contained both consensus binding sequences (Fig. 2B, pp2 region; supplementary material Fig. S2A). Next, we tested whether Bmil transcription required Notch and $\beta$-catenin activities in the normal intestinal crypt cells. By using IHC, we found that Bmil
A

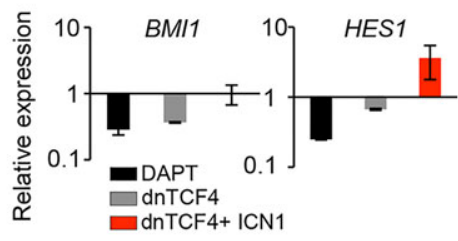

B

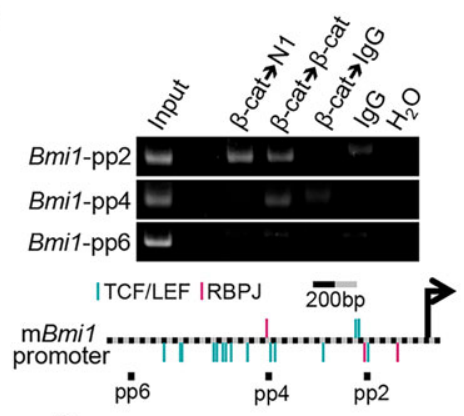

D
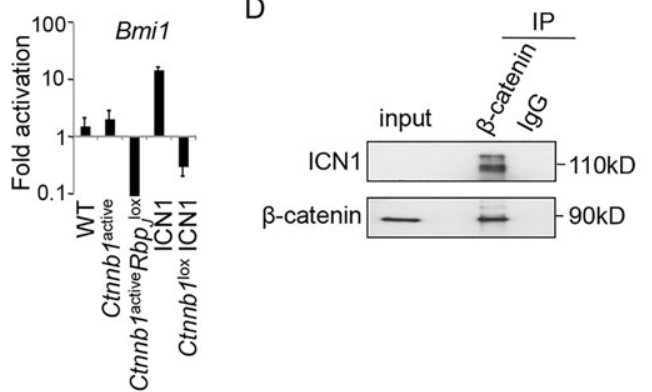

G

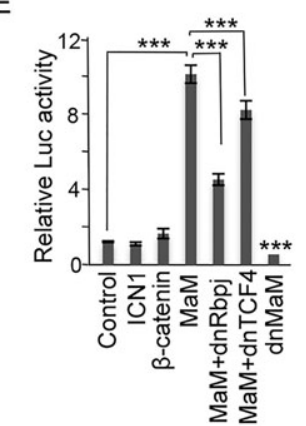

$\mathrm{F}$

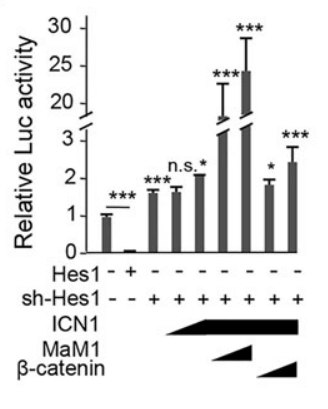

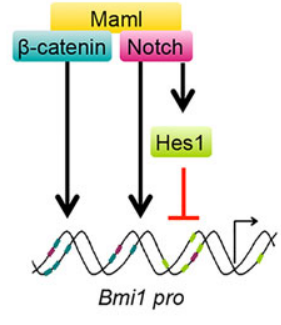

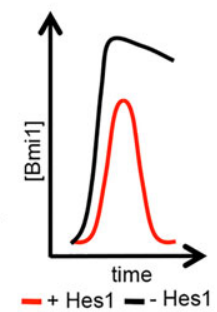

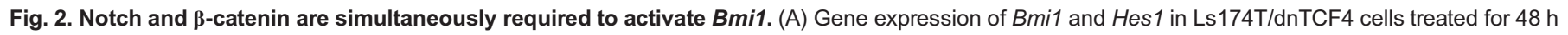
with doxycyline (to induce dnTCF4 and inhibit $\beta$-catenin signaling) or DAPT (Notch and $\gamma$-secretase inhibitor) or both, compared with untreated cells. Expression

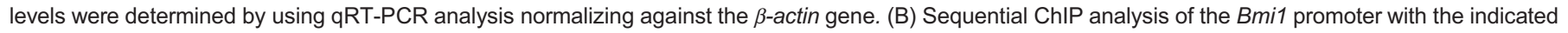
antibodies. Chromatin was isolated from intestinal crypts. Black squares show the relative position of primers in the promoter scheme. (C) IHC (left) and qRT-PCR (right) analyses of Bmi1 in intestinal tissue from the indicated mouse genotypes in the Villin-Cre ${ }^{\text {ER-T2 }}$ background, 4 days after treatment with tamoxifen.

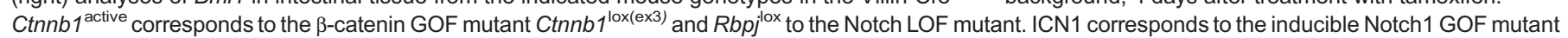
$I C N 1{ }^{\mathrm{LSL}}$. Insets show enlarged images of the boxed areas. (D) Total cell extracts from isolated crypts were precipitated using the anti- $\beta$-catenin antibody. Precipitates were analyzed by western blotting for the presence of active Notch. (E,F) Bmi1 reporter assays to test the effect of the indicated constructs. Increasing amounts of ICN1, MaM1 and $\beta$-catenin constructs were transfected. Dominant-negative (dn)Rbpj and dnTCF4 were used to inhibit Notch and $\beta$-catenin,

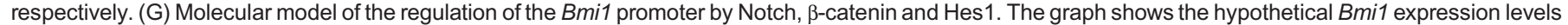
in the presence (red) or absence (black) of Hes1, when both the Notch and Wnt- $\beta$-catenin pathways are active. In $E$ and F, error bars represent the s.d., and statistical significance was determined using Student's $t$-test. ${ }^{*} P<0.05,{ }^{* *} P<0.01$ and ${ }^{* * *} P<0.001$. IP, immunoprecipitation; Maml, Mastermind-like; $m B m i 1$, mouse Bmi1, N1, Notch1; n.s., not significant; pro, promoter; pp, primer pair; sh-Hes1, small hairpin. 
expression was mainly restricted to the intestinal epithelial crypt cells of WT mice (Fig. 2C), where activation of both pathways occurs (Sato et al., 2011). Importantly, specific Rbpj deletion resulted in the total loss of Bmil expression in these cells (data not shown) that was not recovered by the constitutive activation of the $\beta$-catenin pathway (Fig. 2 C). However, $\beta$-catenin was also essential to maintain Bmil expression even in the presence of active Notch1 (Fig. 2C). By co-precipitation of protein extracts from purified intestinal crypts, we demonstrated that endogenous $\beta$-catenin and active Notch1 physically interact in this tissue (Fig. 2D), further supporting the notion of their functional interplay. Next, we generated a reporter construct carrying $2.5 \mathrm{~kb}$ of the proximal Bmil promoter, including the putative Rbpj and TCF consensus sites, fused to the luciferase gene (supplementary material Fig. S2B). We found that pharmacological inhibition of Notch or $\beta$-catenin pathways (by using DAPT or PKF115-584, respectively) (supplementary material Fig. S2C), or the ectopic expression of dominant-negative forms of RBPJ and TCF4 (supplementary material Fig. S2D), were sufficient to repress transcription driven by the Bmil promoter. Conversely, the Notch coactivator Mastermind (MaM) induced this construct in an RBPJ- and TCF4-dependent manner (Fig. 2E), although neither Notch nor $\beta$-catenin alone could induce Bmil-driven transcription, suggesting that MaM was a limiting factor in these cells. By contrast, transcriptional repression through the specific Notch target Hes1 protein is a widely used mechanism for attenuating Notch-dependent transcription (Krejci et al., 2009). We found several Hes consensus binding sites in the Bmil promoter (supplementary material Fig. S2B) that we functionally tested in the reporter experiments. Ectopic Hes1 expression totally abolished Bmil transcription, whereas knockdown of Hes1 increased Bmil reporter activity and facilitated its activation through ICN1, $\beta$-catenin and MaM (Fig. 2F). Our results indicate that Bmil transcription is positively regulated by Notch, $\beta$-catenin and the coactivator MaM, and is repressed by Hes 1 (Fig. 2G), which fine-tunes Bmil levels in response to Notch activation (see Discussion).

By interrogating the whole human and mouse genomes for the frequency of contiguous Rbpj- and TCF-binding consensus sequences, we found that both sequences were not randomly distributed but that they clustered in the promoter region of multiple genes close to their transcription start sites (supplementary material Fig. S2E). Rbpj-binding consensus sites were significantly enriched at distances of 100-200 bp, 300-400 bp and 700-800 bp from the TCFbinding consensus (supplementary material Fig. S2F), compared with not only 1000 randomly permuted site distributions $(P<0.001)$ but also with the $500 \mathrm{bp}$ neighborhood of the observed data $(P=0.001$ for $100-200 \mathrm{bp}$ and $300-400 \mathrm{bp} ; P=0.002$ for $700-800 \mathrm{bp}$ ), indicative of a conserved mechanism for Notch and Wnt co-regulation.

\section{Bmi1-deficient mice display intestinal defects that resemble a Notch LOF phenotype}

Bmil protein is detected in different intestinal crypt cells, including the long-term ISC population (Sangiorgi and Capecchi, 2008); however, the functional significance of Bmil in intestinal homeostasis has not been addressed. Bmil-deficient mice are born at Mendelian ratios but die prematurely (around 2-3 months of age), presenting growth retardation and stem cell-associated defects (Bruggeman et al., 2005; Molofsky et al., 2005; Oguro et al., 2006). We analyzed the intestine of Bmil KO mice at 2-3 months of age and found that the small intestine was significantly shorter $(35.88 \pm 2.3 \mathrm{~cm}$ in the WT and $28.33 \pm 2.5 \mathrm{~cm}$ in the KO, $P<0.001$ ) (Fig. 3A) and thinner (Fig. 3B) compared with that of WT littermates, and a similar length defect was found in the colon $(7.05 \pm 1.0 \mathrm{~cm}$ in the WT and $5.5 \pm 1.2 \mathrm{~cm}$ in the $\mathrm{KO}$,
$P=0.04$ ) (Fig. 3A). Through IHC analysis of Ki67 expression and Alcian Blue staining (Fig. 3C,D), as well as the use of a 5-bromo-2'deoxyuridine $(\mathrm{BrdU})$ proliferation assay (supplementary material Fig. $\mathrm{S} 3 \mathrm{~A}$ ), we observed that Bmil mutants display a significant reduction in the number of cycling crypt cells in both the small intestine and the colon. This observation was associated with a moderate but significant increase in goblet cell differentiation, partially resembling the phenotype obtained upon Rbpj (Notch) deficiency. Double staining for BrdU and the ISC marker Olfm4 demonstrated that proliferation defects involved both the ISC $(3.1 \pm 2.2 \mathrm{BrdU}$ and Olfm4 doublepositive cells in the WT compared with $1.0 \pm 1.6$ in the KO; $P<0.001$ ) and, to a minor extent, the transit-amplifying compartment $(6.9 \pm 3.4$ BrdU-positive cells in the WT compared with $6.3 \pm 3.6$ in the $\mathrm{KO}$, $P=0.17$ ) (Fig. 3E). Comparable results were obtained through the analysis of the cell cycle profile of intestinal crypt populations expressing different levels of the surface marker Ephb2; ISCs were included in the Ephb2 $2^{\text {high }}$ population, and most of the transitamplifying cells were included in the Ephb2 ${ }^{\text {medium }}$ population (Jung et al., 2011) (Fig. 3F). The intestinal phenotype of Bmil-deficient mice was not exclusive of adult animals, but it was already detectable at day 3 after birth (supplementary material Fig. S3B,C), indicating that it originates during development. Consistent with the alterations of the colonic tissue, Bmil protein was also detected in cells located at the bottom of the WT colonic crypts (supplementary material Fig. S3D), which has not been reported previously.

Next, we determined the expression levels of different stem cell markers in the intestinal crypts of Bmil-deficient mice. Using IHC and quantitative reverse-transcriptase (qRT) PCR analyses, we did not find any significant change in the expression levels of the Lgr5, Olfm4, Ephb2, c-Myc, Hopx and Lrig1 genes in the Bmildeficient intestines (Fig. 3G,H). However, Tert, recently identified as a marker for slow-cycling intestinal stem cells in mice, was significantly downregulated in the Bmil-deficient crypt cells (Fig. $3 \mathrm{H})$, which could indicate altered long-term self-renewal.

\section{Bmi1 or Notch deficiency results in increased expression of the cell cycle regulators $\mathrm{p} 16^{\mathrm{INK} 4 \mathrm{a}}$ and $\mathrm{p} 19^{\mathrm{ARF}}$}

Because most of the stem cell defects that have been previously identified in the Bmil $\mathrm{KO}$ mice are associated with upregulation of $p 16^{I N K 4 a}$ and $p 19^{A R F}$, which are targets of Bmil repression, we next determined their levels in the intestinal crypts of our different mutant mice. By using IHC (Fig. 4A,C) and qRT-PCR (Fig. 4D) analyses, we found that $\mathrm{p} 16^{\mathrm{INK} 4 \mathrm{a}}$ and $\mathrm{p} 19^{\mathrm{ARF}}$ levels were significantly increased in the absence of Bmil, which might account for the observed decrease in ISC proliferation. Similarly, the number of intestinal $\mathrm{p} 16^{\mathrm{INK} 4 \mathrm{a}}$-positive cells was significantly increased in the absence of $R b p j$, both in the single LOF and the composite $\beta$-catenin GOF and Rbpj LOF mutants (Fig. 4B,C). By contrast, the highly proliferative $C$ tnnb $1^{\text {lox(ex3) }}$ transgenic intestines did not show any increase in $\mathrm{p} 16^{\mathrm{INK} 4 \mathrm{a}}$ expression. These results strongly suggest that Bmi1, downstream of Notch and $\beta$-catenin, contributes to the regulation of ISC and progenitor proliferation either directly or through $\mathrm{p} 16^{\mathrm{INK} 4 \mathrm{a}}$ and $\mathrm{p} 19^{\mathrm{ARF}}$.

Because Bmil protein is involved in the regulation of the stem cell compartments in other tissues, including the blood, we considered the possibility that the intestinal defects observed in the general Bmildeficient mice were of systemic origin (instead of tissue autonomous). To test this, we generated a Villin-Cre;Bmil $1^{\text {lox/lox }}$ line in which the Bmil gene was specifically deleted in the intestinal epithelium (although more efficiently in the duodenum than in the distal ileum and colon, data not shown). IHC analysis of 3- to 4-week-old intestinal-specific Bmil KO mice showed a consistent and significant 
A

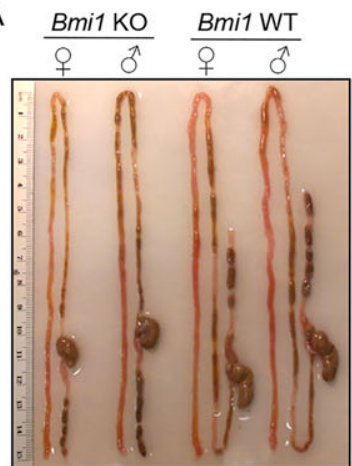

B
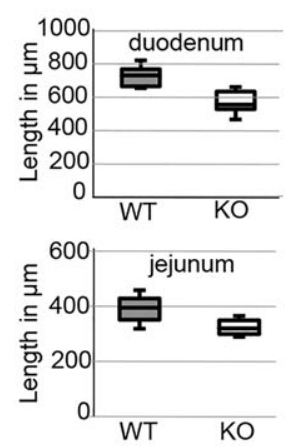

C

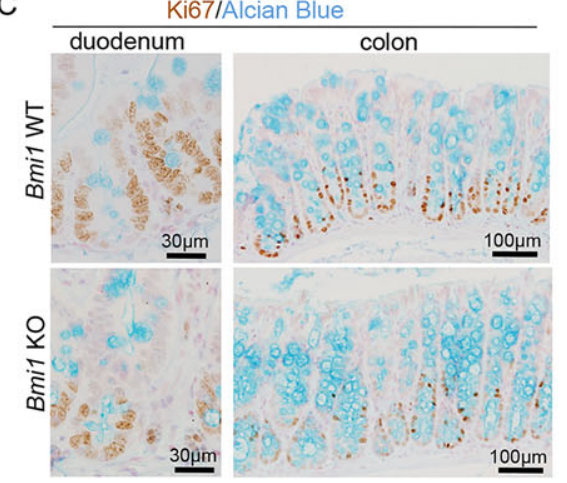

D

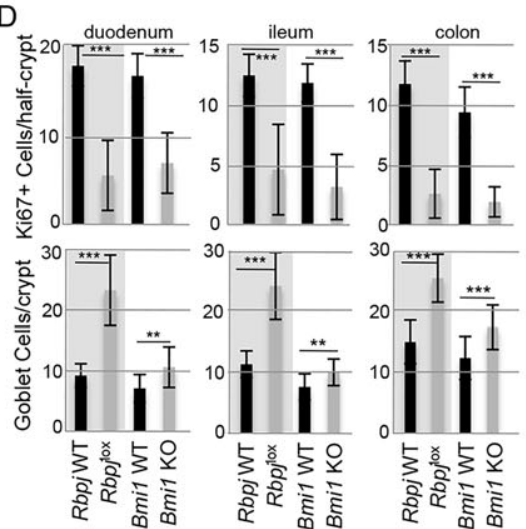

E Olfm $4 / \mathrm{BrdU}(2 \mathrm{~h})$
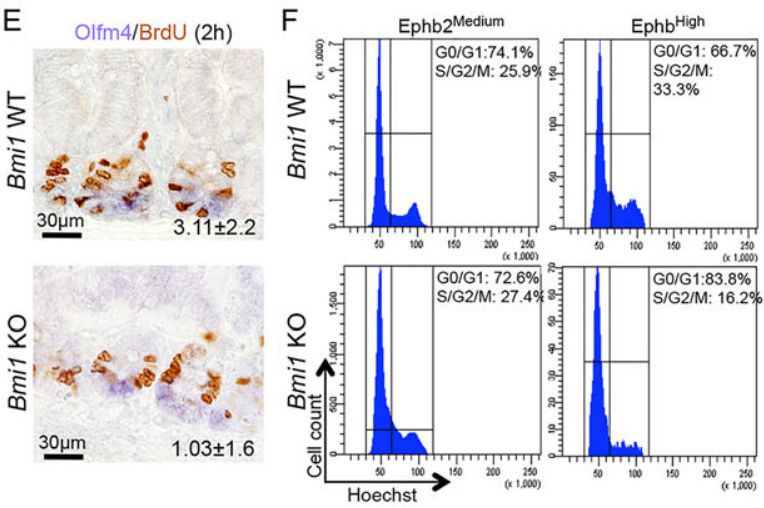

G

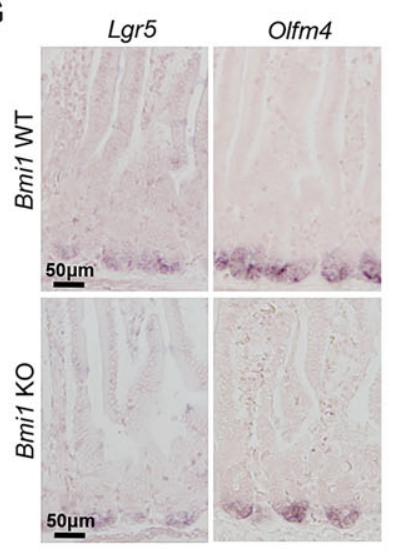

$\mathrm{H}$

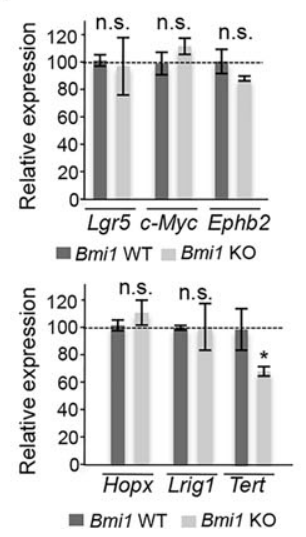

Fig. 3. Bmi1-deficient mice display intestinal abnormalities that partially overlap with the effects of Notch deficiency. (A) Photograph of

intestines from 2-month-old mice of the indicated genotypes and sex.

(B) Quantification of the crypt-villus axis length in the intestines of WT and Bmi1 $\mathrm{KO}$ mice. (C) IHC analysis showing Ki67-positive proliferating cells and Alcian Blue-stained goblet cells in the duodenum and colon of the indicated genotypes. (D) Quantification of the number of proliferating cells and goblet cells in the different regions of the intestine of Bmi1 WT or KO mice, compared with those of the Rbpjdeficient animals (a minimum of 50 crypts per region were counted in each case). Note the slight variability found in the WT animals from different genetic backgrounds. (E) Detection of BrdUpositive cells ( $2 \mathrm{~h}$ after BrdU injection) in the ISC compartment, identified by the expression of Olfm4 through ISH analysis. The average number and s.d. of double-positive cells per crypt, from 30 crypts counted for each genotype, is indicated. $(\mathrm{F})$ Cell cycle profile of the Ephb2 ${ }^{\text {high }}$ and Ephb2 ${ }^{\text {medium intestinal }}$ cell populations from WT and Bmi1 KO animals. One representative from two independent experiments is shown.

(G) ISH analysis of the indicated ISC genes in Bmi1 WT or KO mice.

(H) Quantification by using qRT-PCR analysis of the mRNA levels in the crypt fractions. In $\mathrm{B}, \mathrm{D}$ and $\mathrm{H}$, error bars represent the s.d., and statistical significance was determined using Student's $t$-test. ${ }^{*} P<0.05,{ }^{* *} P<0.01$ and ${ }^{* * *} P<0.001$. n.s., not significant. accumulation of $\mathrm{p} 16^{\mathrm{INK} 4 \mathrm{a}}$-positive cells along the whole crypt-villus axis, which was associated with a reduction in the number of proliferating Ki67-positive cells when compared with that of their WT littermates (Fig. 4E). However, we did not detect a consistent reduction in the size of the tissue-specific $\mathrm{KO}$ intestines when compared with those found in the conventional Bmil null mice.

In agreement with the possibility that intestinal defects that are associated with Bmil deficiency originate during embryonic development, we found a massive increase in $\mathrm{p} 16^{\mathrm{INK} 4 \mathrm{a}}$ levels and a reduction in the number of Ki67-positive cells in the embryonic intestine at the time of villus formation (embryonic days 15 and 16) (Fig. 4E; supplementary material Fig. S3E).

\section{The Bmi1-deficient phenotype mimics that of Notch inhibition with respect to the self-renewal and DNA repair capacity of ISCs}

We performed serial culture assays of intestinal organoids (Sato et al., 2009) to further study the requirement of Bmil in ISC function. Intestinal organoids are derived from ISC and can be maintained indefinitely after serial passaging. We found that serially replated organoids (after passage 10) contain a high number of Bmil-expressing cells (Fig. 5A, right panels), which was reduced following Notch inhibition by using DAPT (Fig. 5A,B). This was before the failure of organoid growth that occurred at around 3-4 days of treatment with DAPT (Fig. 5A, left panels). Interestingly, Notch inhibition in these cultures led to the transcriptional activation of $p 16^{I N K 4 a}$ and $p 19^{A R F}$ (Fig. 5C) that was concomitant with a reduction in the mRNA levels of Olfm 4 and Ascl2 (supplementary material Fig. S4A).

We next isolated intestinal crypt cells from Bmil-deficient mice to measure their clonogenic capacity. Bmil-deficient crypt cells generated organoids at a similar efficiency to their WT counterparts, but their replating capacity gradually declined from passage 5-7, and they failed to grow after passage 15-16 (Fig. 5D; supplementary material Fig. S4B). Associated with their defective long-term selfrenewal, mutant organoids at passage $12-15$ contained a significant 


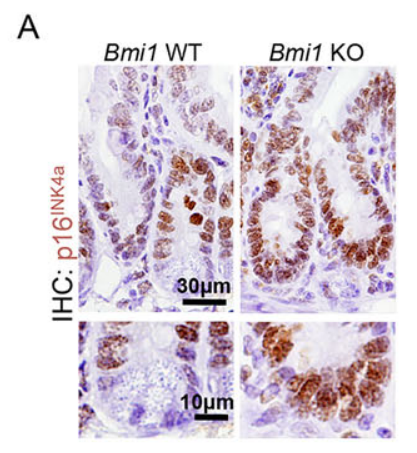

B

C

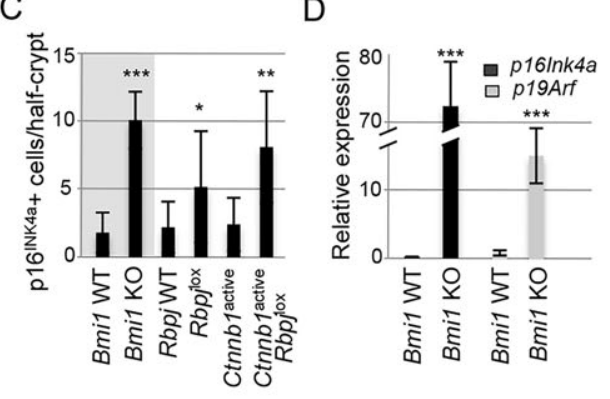

$\mathrm{F}$

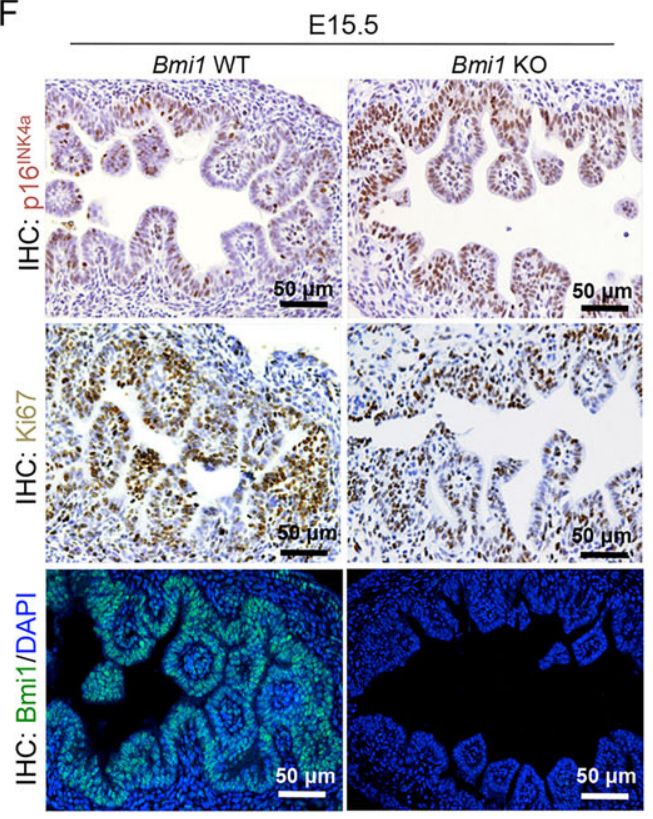

Fig. 4. Increased $\mathrm{p} 16^{\mathrm{INK} 4 \mathrm{a}}$ in the intestine of Bmi1-deficient or Rbpj-deficient mutants.

(A) IHC analyses showing p16 ${ }^{\text {INK4a }}$ levels and distribution in the intestine of Bmi1 WT and KO mouse. (B) IHC showing p16 ${ }^{\text {INK4a }}$ levels and distribution in the intestine of the indicated mouse genotypes. (C) Quantification of the number of cells per intestinal crypt displaying nuclear $\mathrm{p} 16^{\mathrm{INK} 4 \mathrm{a}}$ staining. In B and C,

Ctnnb $1^{\text {active }}$ corresponds to the $\beta$-catenin GOF mutant Ctnnb $1^{\text {lox(ex3) }}$ and $R b p j^{\text {lox }}$ to the Notch LOF mutant. (D) Quantification of qRT-PCR analyses of the $p 16^{I N K 4 a}$ and $p 19^{A R F}$ mRNA levels in Bmi1 WT and KO crypt fractions. Genes for $\beta 2$ microglobulin, GAPDH and villin were all used for normalization. (E) IHC analyses showing $\mathrm{p} 16^{\mathrm{INK} 4 \mathrm{a}}$ and Ki67 levels of intestinal epithelial-specific Bmi1-deficient mice. The graph shows the quantification of Ki67-positive cells per crypt (a minimum of 30 crypts were counted for each sample, $n=3$ ).

(F) IHC analyses of $\mathrm{p} 16^{\mathrm{INK} 4 \mathrm{a}}$, Ki67 and Bmi1 (the latter a control for the lack of protein expression) in Bmi1 WT and null intestines at embryonic day (E)15.5. In C-E, error bars represent the s.d., and statistical significance was determined using Student's $t$-test. ${ }^{*} P<0.05,{ }^{* *} P<0.01$ and ${ }^{* * *} P<0.001$. number of terminal deoxynucleotidyl transferase dUTP nick end labeling (TUNEL)-positive cells in the epithelial layer that were mostly negative for active caspase 3 staining (Fig. 5E), suggesting that Bmil deficiency favors the accumulation of DNA breaks independently of apoptosis. To validate this finding, we determined the DNA repair capacity of Bmil-deficient intestinal cells in response to $\gamma$-irradiation in vivo. With this aim, we irradiated Bmil WT or KO littermates with $12 \mathrm{~Gy}$, which were then killed $2 \mathrm{~h}$ later and processed for IHC analysis with an antibody against $\gamma \mathrm{H} 2 \mathrm{~A} . \mathrm{X}$. We found that WT intestines specifically accumulate $\gamma \mathrm{H} 2 \mathrm{~A}$.X staining in the villus regions, which is an indication of unrepaired DNA breaks. However, intestinal crypt cells only showed discrete $\gamma \mathrm{H} 2 \mathrm{~A}$.X foci as a result of efficient DNA repair, as previously published (Hua et al., 2012). By contrast, Bmildeficient intestines displayed an intense homogeneous $\gamma \mathrm{H} 2 \mathrm{~A} . \mathrm{X}$ staining pattern arising from the base of the crypts to the top of the villi (Fig. 5F), indicating that Bmil protein is involved in regulating
DNA damage repair in the intestinal crypt cells. This is consistent with the known role of Bmil protein in DNA damage repair through $\mathrm{H} 2 \mathrm{~A}$ monoubiquitylation, which facilitates the recruitment of the repair machinery (Ginjala et al., 2011; Ismail et al., 2010; Pan et al., 2011).

Taken together, our results indicate that Notch signaling exerts a direct effect on the maintenance of ISCs that involves a direct cooperation with $\beta$-catenin at the chromatin level to regulate gene transcription. We identify Bmil as target of both Notch and $\beta$-catenin and demonstrate that intestinal Bmil deficiency results in reduced proliferation and limited self-renewal of the ISCs (see model in Fig. 5G).

\section{DISCUSSION}

We have identified a new mechanism for gene regulation that depends on the simultaneous activity of two crucial signaling pathways, Wnt- $\beta$-catenin and Notch, and is functional in the normal 
A

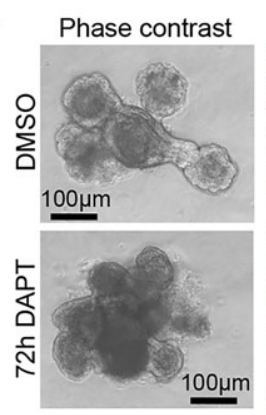

E

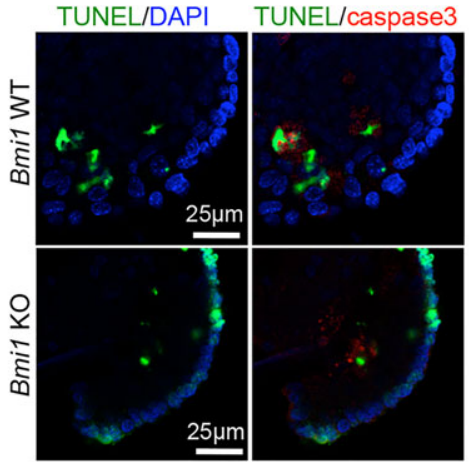

B

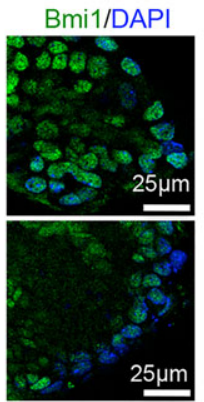

TUNEL/caspase3

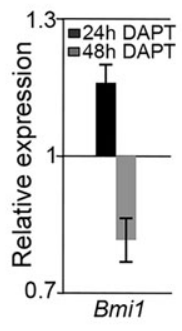

C

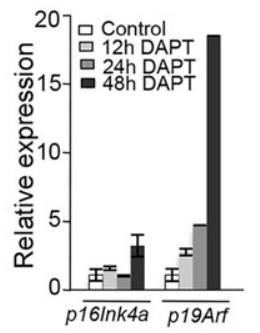

D

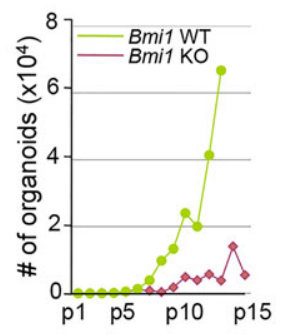

F

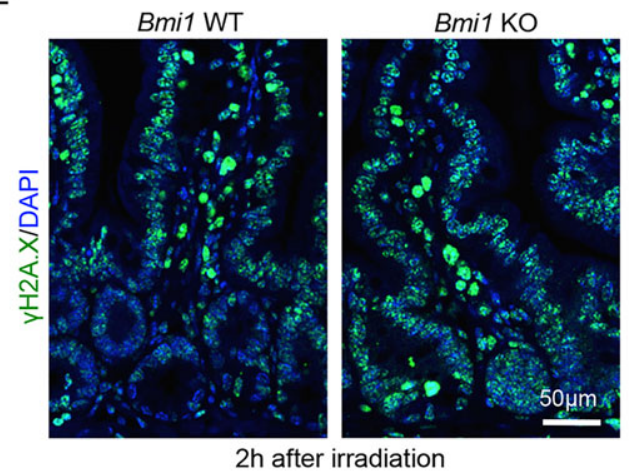

G

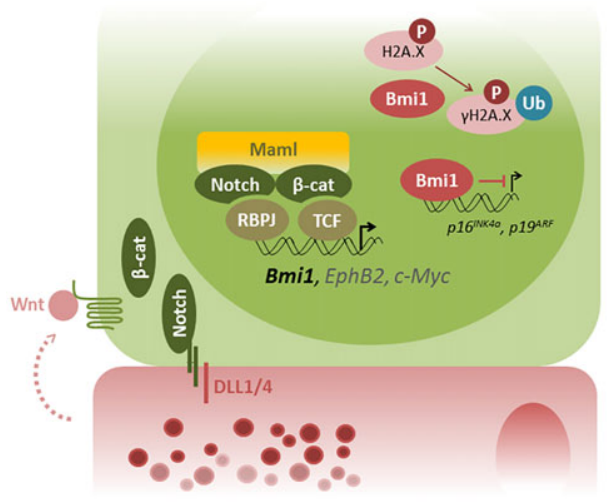

Fig. 5. The Notch inhibition phenotype mimics that of Bmi1 deficiency with respect to the self-renewal and DNA repair capacity of ISCs. (A) Representative image of vehicle- or DAPT-treated organoid cultures at $72 \mathrm{~h}(n=3)$. Right panels show Bmi1 protein in both conditions. (B,C) Expression levels of $B m i 1 p 16^{I N K 4 a}$ and $p 19^{A R F}$ as determined by qRT-PCR analyses of organoids treated as indicated. The relative expression was normalized against the gene encoding $\beta 2$ microglobulin. In all these experiments organoids were grown for 5 days before treatment. A representative of three independent experiments is shown. (D) The cumulative number of organoids obtained from WT and Bmi1-deficient crypt cells after passage (p)15. One representative of two independent experiments is shown. (E) Double staining of the cleaved caspase3 and TUNEL assay to determine the amount of apoptosis and DNA damage in WT and Bmi1 KO organoids at passage 15, representative of three independent experiments. $(F) \gamma H 2 A . X$ immunofluorescence of Bmi1 WT and KO intestines collected $2 \mathrm{~h}$ after whole-animal irradiation (12 Gy). (G) Model of Bmi1 regulation by Wnt and Notch signals supplied by adjacent Paneth cells. In B and C, error bars represent the s.d., and statistical significance was determined using Student's $t$-test. ${ }^{*} P<0.05,{ }^{* *} P<0.01$ and ${ }^{* * *} P<0.001$. $\beta$-cat, $\beta$-catenin; Maml, Mastermind-like; Ub, ubiquitin.

intestinal crypts. Importantly, we have identified Bmil as a target of both $\beta$-catenin and Notch, and characterized its function in ISCs. Accordingly, Bmil has been previously identified as a Wnt and KLF4 target in colorectal cancer cells (Yu et al., 2012). We found that Bmil deficiency only reproduces some of the defects that are associated with Notch inhibition, including altered proliferation and increased crypt cell differentiation into secretory cells, indicating that many other genes downstream of Notch are also required for ISC function. Moreover, Bmil helps to maintain the DNA integrity and self-renewal capacity of the ISC population in vitro, which should be further investigated in relation to the Notch pathway.
Wnt and Notch are well-known stem cell regulators in many different systems, having synergic or antagonistic effects that are context dependent. In the intestine, both pathways are required to maintain the undifferentiated compartment (Ireland et al., 2004; Korinek et al., 1998; Riccio et al., 2008; van Es et al., 2005). Nevertheless, the contribution of each signal and their orchestration is still under debate. Our results indicate that both pathways need to be simultaneously active to maintain the stem cell compartment, but suggest that this evolutionary strategy might be of general use, as indicated by the non-random distribution of TCF- and Rbpj-binding consensus sites along the entire mouse and human genomes. In this 
work, we focused on studying Bmil, the expression of which depends on Notch- and $\beta$-catenin-mediated signaling, and we demonstrate that the Bmil promoter is directly regulated by both factors in association with the MaM coactivator. Conversely, the Notch target gene Hes1, which is also a master regulator of the absorptive and secretory lineage differentiation, represses Bmil, suggesting that its expression is dynamically regulated in the crypt through the participation of both positive and negative signals. Notch has been previously shown to control this type of regulatory loop, also known as type I incoherent feed-forward loops (I1-IFF) in Drosophila (Guiu et al., 2013; Krejci et al., 2009).

Although the original identification of Bmil as a target of both Notch and $\beta$-catenin was based in the use of cancer cell lines, this regulation is also found in a physiological context, such as the ISCs. Bmil function was known to be crucial for hematopoietic and neural stem cells, but its role in the intestine has not been defined previously. We here show that Bmil deletion results in reduced intestinal size, associated with increased differentiation into goblet cells and reduced proliferation of the stem cell compartment, a phenotype that partially overlaps with that produced by the absence of Notch or Rbpj signaling in the ISC compartment. Although Bmil null mice show a decrease in body weight, we cannot exclude that this is a secondary effect of defective intestinal function. However, several ISC markers are still detected in the intestine of Bmildeficient animals, and this tissue is maintained for at least 3 months (the life expectancy of these animals), which is very different from the strong intestinal phenotype that is associated with complete Notch and/or $\beta$-catenin depletion. This fact reflects the functional relevance of other Notch and $\beta$-catenin targets, such as Ephb2 or c-Myc in ISC maintenance. Of note, the severity of the Notch deletion phenotype might vary among different genetic backgrounds, as reflected by the work of Yin and colleagues (Yin et al., 2014).

By culturing normal or Bmil-deficient ISC in Matrigel, we here demonstrate that intestinal crypt cells from $\mathrm{Bmil}$-deficient animals have incomplete self-renewal capacity associated with increased DNA damage repair, a phenotype that was confirmed in the irradiated Bmil-deficient intestines and is in agreement with the identification of the Bmil-positive cells as a radio-resistant population with capacity to replace Lgr5-positive cells after radiation (Yan et al., 2012). Inhibition of Notch in the organoid cultures results in Bmil downregulation, upregulation of $p 16^{I N K 4 a}$ and $p 19^{A R F}$ and a reduced number of Ki67-positive cells, before terminal organoid differentiation. These results suggest that Bmi1 contributes to proliferation and self-renewal downstream of Notch and $\beta$-catenin, probably by regulating the cell cycle through p $16^{\mathrm{INK} 4 \mathrm{a}}$ and $\mathrm{p} 19^{\mathrm{ARF}}$, DNA repair (Ismail et al., 2010), telomere length (Dimri et al., 2002; Jacobs and de Lange, 2004) and senescence (Park et al., 2004), which are known functions of Bmil.

\section{MATERIALS AND METHODS}

\section{Animals}

All animal work was conducted according to the guidelines from Generalita de Catalunya, and this study was approved by the committee for animal experimentation at Institut Hospital del Mar d'Investigacions Mèdiques (Barcelona, Spain). The mouse transgenic line Villin-Cre ${ }^{\text {ER-T2 }}$ (in the C57BL/6 background), in which Cre recombinase expression is confined to the intestinal epithelium, was crossed with the different floxed mice to generate intestine-specific gene-targeted mice. The Cre ${ }^{\mathrm{ER}-\mathrm{T} 2}$ recombinase activity was induced by injecting 2- to 3-week-old mice with tamoxifen $(10 \mathrm{mg} / \mathrm{kg}$ body weight in corn oil; Sigma) intraperitoneally for three consecutive days. The general Bmil null mice were in an FVB/NJ background. Intestine-specific $B m i 1 \mathrm{KO}$ animals were obtained by crossing the previously described Bmil ${ }^{\text {lox }}$ (Arranz et al., 2012) with the Villin-Cre (from Jackson Laboratories) line (both in C57BL/6 background). In all the experiments using Bmil-deficient mice, animals were euthanized before any obvious sign of disease was detected.

\section{Cell lines and reagents}

Cell lines expressing dominant-negative TCF4 (Ls174T/dnTCF4) and ICN1 (Ls174T/dnTCF4/ICN1) have been previously described (Rodilla et al., 2009; van de Wetering et al., 2002) and were maintained in Dulbecco's media with $10 \%$ fetal bovine serum (FBS). Doxycycline (Sigma) was used at $1 \mu \mathrm{g} / \mathrm{ml}$. The $\gamma$-secretase inhibitor DAPT (Calbiochem) was used at $25 \mu \mathrm{M}$.

\section{RT-PCR}

Total RNA was extracted with the RNeasy Qiagen kit, and RT-First Strand cDNA Synthesis kit (Amersham Pharmacia Biotech) was used. The primers used for RT-PCR analyses are listed in supplementary material Table S1A. qRT-PCR was performed in a LightCycler480 system using SYBR Green I Master kit (Roche).

\section{ChIP}

Briefly, chromatin from cross-linked cells was sonicated, incubated overnight with the indicated antibodies in radioimmunoprecipitation assay (RIPA) buffer and precipitated with protein G/A-Sepharose. Cross-linkage of the coprecipitated DNA-protein complexes was reversed, and DNA was used as a template for the PCR. Antibodies against cleaved Notch1 (ab8925, Abcam) and $\beta$-catenin (BD Bioscience, catalog no. 61054) were used. For second ChIP experiments, complexes from the first ChIP were eluted through incubation in $25 \mu \mathrm{l}$ of $10 \mathrm{mM}$ dithiothreitol for $30 \mathrm{~min}$ at $37^{\circ} \mathrm{C}$. After centrifugation, the supernatant was diluted with RIPA buffer and subjected to the ChIP procedure. The primers used are listed in supplementary material Table S1B

\section{In situ hybridization (ISH)}

Intestinal samples were flushed gently with cold PBS and fixed overnight in $4 \%$ paraformaldehyde at room temperature. Samples were then dehydrated, embedded in paraffin and sectioned at $8 \mu \mathrm{m}$. After de-waxing and rehydration, the samples were treated with $0.2 \mathrm{~N} \mathrm{HCl}$ and proteinase $\mathrm{K}$ $(30 \mu \mathrm{g} / \mathrm{ml})$. Samples were hybridized for $24 \mathrm{~h}$ at $65^{\circ} \mathrm{C}$. After washing, blocking solution was added (blocking reagent, Roche) and incubation with an antibody against digoxigenin was performed overnight at $4^{\circ} \mathrm{C}$. Next morning, samples were washed and developed with NBT/BCIP (Roche). The RNA probes were obtained from complementary DNA of mouse c-Myc, Hes1, Olfm 4, Ascl2 and Lgr5, and were generated through in vitro transcription with a Digoxigenin RNA Labeling Kit (Roche) according to the manufacturer's instructions.

\section{Intestinal crypt isolation and organoid culture in Matrigel}

Mouse small intestines were collected, sliced longitudinally and thoroughly washed in cold PBS. Villi were removed by carefully scraping the surface. Remaining tissue was cut into small sections, treated twice with $2 \mathrm{mM}$ EDTA for $30 \mathrm{~min}$ and centrifuged at $110 \mathrm{~g}$ to obtain the crypt-enriched fraction as previously described (Sato et al., 2009). Approximately $10^{5}$ cells were seeded in $50 \mu \mathrm{l}$ Matrigel (BD Biosciences) in 24-well plates. After polymerization, $500 \mu 1$ of complete organoid medium [(DMEM/F12, Biological Industries) with penicillin $(100 \mathrm{U} / \mathrm{ml})$ and streptomycin $(100 \mu \mathrm{g} / \mathrm{ml})$ (Biological Industries) supplemented with N2 and B27 (Invitrogen) containing $140 \mathrm{nM}$ ROCK inhibitor (Y27632, Sigma), $100 \mathrm{ng} / \mathrm{ml}$ Noggin (Peprotech), $100 \mathrm{ng} / \mathrm{ml}$ R-spondin (R\&D Systems), $50 \mathrm{ng} / \mathrm{ml}$ EGF (Sigma) and $20 \mathrm{ng} / \mathrm{ml}$ basic FGF (Peprotech)] was added. Medium was changed every 2 days. Incubator conditions were $37^{\circ} \mathrm{C}$, $5 \% \mathrm{CO}_{2}$.

\section{Organoid immunostaining}

Organoids were collected from Matrigel (BD Bioscience), placed onto a slide by using cytospin and circled with DakoPen (Dako). Whole-mount immunostaining was performed after fixation with $4 \%$ paraformaldehyde 
and permeabilization with $0.3 \%$ Triton X-100 (Pierce). Organoids were stained with an antibody against $\gamma \mathrm{H} 2 \mathrm{~A} . \mathrm{X}$ (1:200; Cell Signaling, catalog no. 2577) overnight and then incubated with secondary antibody donkey-anti-rabbit Alexa Fluor 488 (Molecular Probes) for $2 \mathrm{~h}$ at room temperature at a 1:1000 dilution. Slides were mounted in VectaShield with DAPI (Vector). Other antibodies used were: anti-Bmi1 (1:100; Abcam, ab14389), followed by donkey anti-mouse Alexa Fluor 488, and anticleaved caspase3 (1:500; Cell Signaling, catalog no. 9661).

\section{TUNEL assay}

The TUNEL assay was performed using the DeadEnd Colorimetric Apoptosis Detection System (Promega), according to the manufacturer's instructions.

\section{Image analysis}

IHC of intestinal sections was observed by using an Olympus BX61 microscope, and images were taken using the cellSens Digital Imaging software. Measurement of intestinal thickness was performed using the Aperio ImageScope Image Analysis Platform. Immunofluorescence images of intestinal sections and organoids were taken by using confocal microscopy with a Leica SP5 TCS upright microscope and the Leica Application Suite Advanced Fluorescence software.

\section{Immunoprecipitation assays}

Purified intestinal murine crypt cells were lysed for $30 \mathrm{~min}$ at $4^{\circ} \mathrm{C}$ in $300 \mu$ PBS plus $0.5 \%$ Triton X-100, $1 \mathrm{mM}$ EDTA, $100 \mathrm{mM}$ sodium orthovanadate, $0.25 \mathrm{mM}$ PMSF and complete protease inhibitor cocktail (Roche). Supernatants were pre-cleared for $2 \mathrm{~h}$ with $1 \%$ bovine serum albumin (BSA), $1 \mu \mathrm{g}$ IgGs and $50 \mu \mathrm{l}$ sepharose protein A (SPA) beads and incubated overnight with $3 \mu \mathrm{g}$ of specific anti- $\beta$-catenin antibody. Antibody-protein complexes were then captured with $30 \mu \mathrm{l}$ SPA beads for $2 \mathrm{~h}$, extensively washed in lysis buffer, and the precipitates were analyzed by western blotting.

\section{Bioinformatics analysis}

The human genome was scanned for the detection of Rbpj-([CG][CT] GTGGGAA[AC]) and TCF4- (G[TA][TA]CAA[TA]GGG) binding sites in both forward or reverse strands using a modified version of a previously described algorithm (Roman et al., 2008) that identifies local genomic regions with colocalization of several binding sites. $P$ values were obtained by the $Z$-scores derived from observed and permuted distributions of the binding sites. Graphs and statistics were built with R Statistical package.

\section{Promoter analysis and luciferase assays}

The Bmil-luc reporter was generated by cloning the region from -2009 to +484 of the human Bmil gene into the pGL2 basic vector (Promega), which was then verified by sequencing. The primers used were GLprimerl and GLprimer2 from Promega. Luciferase reporter assays were performed in HEK-293T cells. Cells were seeded in 12 -well plates at a density of $5 \times 10^{4}$ cells/well. In the different experiments, $250 \mathrm{ng}$ or the indicated amounts of ICN1, Mastermind, dominant-negative Rbpj, dominant-negative TCF4, small hairpin RNA against Hes1 (shHes1; MISSION, TRCN0000018989) or irrelevant DNA, plus $150 \mathrm{ng}$ RSV- $\beta$-galactosidase and Bmil promoterluciferase (Bmipro-luc) plasmids were transfected into triplicate wells using polyethylenimine (PEI) (Polysciences). Where indicated, HEK-293T cells were treated with $\gamma$-secretase inhibitor or DAPT (Calbiochem) at a $50 \mu \mathrm{M}$ final concentration for $72 \mathrm{~h}$ before transfection and during the assay for $24 \mathrm{~h}$ with the $\beta$-catenin inhibitor PKF115584 at $0.66 \mu \mathrm{M}$ (kindly given by Novartis). Luciferase activity was measured after $48 \mathrm{~h}$ of transfection following the manufacturer's instructions (Luciferase Assay System, Promega). Expression levels of transfected proteins were verified by western blotting.

\section{Immunohistochemistry}

Intestinal samples were embedded in paraffin and sectioned at $4 \mu \mathrm{m}$. After de-waxing and rehydration, endogenous peroxidase activity was quenched (20 min, $1.5 \% \mathrm{H}_{2} \mathrm{O}_{2}$ ) and antigen retrieval was performed depending on the antibody. Paneth cells were stained with a rabbit antibody against lysozyme
(1:5000; Dako, A0099). Goblet cells were stained with Alcian Blue ( $\mathrm{pH}$ 2.5; Sigma) and counterstained with Nuclear Fast Red (Sigma). Other primary antibodies were against: green fluorescent protein (1:200; Takara, 632460); $\beta$-catenin (1:2000; Sigma, C2206); Bmi1 (1:200; Abcam, ab14389); EphB2 (1:500; R\&D Systems); Myc (1:100; Santa Cruz, sc-764); Ki67 (1:500; Novocastra, MM1); p16 ${ }^{\mathrm{INK} 4 \mathrm{a}}$ (1:50; Santa Cruz, sc-1207; or 1:150; Santa Cruz, sc-1661). All primary antibodies were diluted in PBS containing $0.05 \% \mathrm{BSA}$ and incubated overnight at $4^{\circ} \mathrm{C}$, unless indicated otherwise. Sections were then incubated with specific horseradish peroxidase (HRP)labeled secondary antibody, and staining was developed using diaminobenzidine peroxidase substrate kit (Dako Cytomation). BrdU (1:250; Abcam, ab6326) was incubated for $2 \mathrm{~h}$ at room temperature, and the secondary antibody system used was a biotinylated anti-rat antibody (Dako, E0468) incubated for $1 \mathrm{~h}$ at room temperature, followed by the Vectastain ABC kit (Vector, PK6100). Staining was developed as described above. For staining with antibodies against cleaved Notch1 (1:200; Cell Signaling, no. 4147) and Bmil (Cell Signaling, no. 6964), incubations were performed in histoblock solution (PBS 3\% BSA, $20 \mathrm{mM} \mathrm{MgCl}_{2}, 0.3 \%$ Tween 20,5\% FBS), and for staining of $\gamma \mathrm{H} 2 \mathrm{~A} . \mathrm{X}$ (1:200; Cell Signaling, no. 2577), incubations were performed in PBS 1\% normal goat serum (Dako), $0.1 \%$ surfactant-AMPS (Thermo Scientific) and $0.05 \%$ BSA. Incubations were performed overnight at $4{ }^{\circ} \mathrm{C}$, samples were then incubated with HRP-labeled anti-rabbit polymer (Dako Envision) and developed using FITC-coupled Tyramide Signal Amplification System (PerkinElmer).

\section{Acknowledgements}

We thank Hans Clevers (Hubrecht Institute, Utrecht, The Netherlands) for Ls174T/dnTCF4 cells and Alfons Nonell for Bioinformatics assistance. We thank Maarteen van Lohuizen and the NKI-AVL for the Bmi1 KO mice. Many thanks to Jessica González, Berta Terré and Elena Vila for technical assistance; and all the members of the Stem Cells and Cancer Laboratory for helpful critical discussions.

\section{Competing interests}

The authors declare no competing financial interests.

\section{Author contributions}

E.L.-A., V.R., L.P., J.G., M.I. and A.C.R. designed and performed the experiments. S. Gutarra and S. Gonzalez helped with the animal work. P.M.-C. P.F.-S., F.R., A.B. and L.L.E. designed and supervised the experimental work. A.B. and L.L.E. conceived the study, analyzed the data and wrote the manuscript.

\section{Funding}

Instituto de Salud Carlos III [PI10/01128], Ministerio de Ciencia e Innovación [ACl2009-0918], Agència de Gestió d'Ajuts Universitaris i de Recerca-Convocatòria Estratègica-2010-0006 and Red Temática de Investigación Cooperativa en Cáncer [RD06/0020/0098, RD12/0036/0054] have supported this work. The Mar Institute of Medical Research (IMIM) Foundation financed V.R., and she is a recipient of a European Molecular Biology Organization (EMBO) short-term fellowship [ASTF 20-2010]. E.L.-A. is funded by 'Fundación la Caixa' (2010) and the Department of Education, Universities and Research of the Basque Government [BFI-2011]. L.L.E is an investigator of the Spanish National Health System (SNS) [CES08/006].

\section{Supplementary material}

Supplementary material available online at

http://dev.biologists.org/lookup/suppl/doi:10.1242/dev.107714/-/DC1

\section{References}

Arranz, L., Herrera-Merchan, A., Ligos, J. M., de Molina, A., Dominguez, O. and Gonzalez, S. (2012). Bmi1 is critical to prevent Ikaros-mediated lymphoid priming in hematopoietic stem cells. Cell Cycle 11, 65-78.

Barker, N., van Es, J. H., Kuipers, J., Kujala, P., van den Born, M., Cozijnsen, M., Haegebarth, A., Korving, J., Begthel, H., Peters, P. J. et al. (2007). Identification of stem cells in small intestine and colon by marker gene Lgr5. Nature 449, 1003-1007.

Bigas, A., Guiu, J. and Gama-Norton, L. (2013). Notch and Wnt signaling in the emergence of hematopoietic stem cells. Blood Cells Mol. Dis. 51, 264-270.

Bruggeman, S. W. M., Valk-Lingbeek, M. E., van der Stoop, P. P. M., Jacobs, J. J. L., Kieboom, K., Tanger, E., Hulsman, D., Leung, C., Arsenijevic, Y. Marino, S. et al. (2005). Ink4a and Arf differentially affect cell proliferation and neural stem cell self-renewal in Bmi1-deficient mice. Genes Dev. 19, 1438-1443.

Dimri, G. P., Martinez, J. L., Jacobs, J. J., Keblusek, P., Itahana, K., Van Lohuizen, M., Campisi, J., Wazer, D. E. and Band, V. (2002). The Bmi-1 
oncogene induces telomerase activity and immortalizes human mammary epithelial cells. Cancer Res. 62, 4736-4745.

Espinosa, L., Ingles-Esteve, J., Aguilera, C. and Bigas, A. (2003) Phosphorylation by glycogen synthase kinase-3 beta down-regulates Notch activity, a link for Notch and Wnt pathways. J. Biol. Chem. 278, 32227-32235.

Estrach, S., Ambler, C. A., Lo Celso, C. L., Hozumi, K. and Watt, F. M. (2006) Jagged 1 is a beta-catenin target gene required for ectopic hair follicle formation in adult epidermis. Development 133, 4427-4438.

Fre, S., Hannezo, E., Sale, S., Huyghe, M., Lafkas, D., Kissel, H., Louvi, A., Greve, J., Louvard, D. and Artavanis-Tsakonas, S. (2011). Notch lineages and activity in intestinal stem cells determined by a new set of knock-in mice. PLoS ONE 6, e25785.

Ginjala, V., Nacerddine, K., Kulkarni, A., Oza, J., Hill, S. J., Yao, M., Citterio, E., van Lohuizen, M. and Ganesan, S. (2011). BMl1 is recruited to DNA breaks and contributes to DNA damage-induced $\mathrm{H} 2 \mathrm{~A}$ ubiquitination and repair. Mol. Cell. Biol. 31, 1972-1982.

Guiu, J., Shimizu, R., D'Altri, T., Fraser, S. T., Hatakeyama, J., Bresnick, E. H., Kageyama, R., Dzierzak, E., Yamamoto, M., Espinosa, L. et al. (2013). Hes repressors are essential regulators of hematopoietic stem cell development downstream of Notch signaling. J. Exp. Med. 210, 71-84.

Hayward, P., Brennan, K., Sanders, P., Balayo, T., DasGupta, R., Perrimon, N. and Martinez Arias, A. (2005). Notch modulates Wnt signalling by associating with Armadillo/beta-catenin and regulating its transcriptional activity. Development 132, 1819-1830.

Hua, G., Thin, T. H., Feldman, R., Haimovitz-Friedman, A., Clevers, H., Fuks, Z and Kolesnick, R. (2012). Crypt base columnar stem cells in small intestines of mice are radioresistant. Gastroenterology 143, 1266-1276.

Ireland, H., Kemp, R., Houghton, C., Howard, L., Clarke, A. R., Sansom, O. J. and Winton, D. J. (2004). Inducible Cre-mediated control of gene expression in the murine gastrointestinal tract: effect of loss of beta-catenin. Gastroenterology 126, 1236-1246

smail, I. H., Andrin, C., McDonald, D. and Hendzel, M. J. (2010). BMI1-mediated histone ubiquitylation promotes DNA double-strand break repair. J. Cell Biol. 191 45-60.

Itzkovitz, S., Lyubimova, A., Blat, I. C., Maynard, M., van Es, J., Lees, J., Jacks T., Clevers, H. and van Oudenaarden, A. (2012). Single-molecule transcrip counting of stem-cell markers in the mouse intestine. Nat. Cell Biol. 14, 106-114.

Jacobs, J. J. L. and de Lange, T. (2004). Significant role for p16INK4a in p53independent telomere-directed senescence. Curr. Biol. 14, 2302-2308.

Janzen, V., Forkert, R., Fleming, H. E., Saito, Y., Waring, M. T., Dombkowski, D. M., Cheng, T., DePinho, R. A., Sharpless, N. E. and Scadden, D. T. (2006) Stem-cell ageing modified by the cyclin-dependent kinase inhibitor p16INK4a Nature 443, 421-426

Jensen, J., Pedersen, E. E., Galante, P., Hald, J., Heller, R. S., Ishibashi, M., Kageyama, R., Guillemot, F., Serup, P. and Madsen, O. D. (2000). Control of endodermal endocrine development by Hes-1. Nat. Genet. 24, 36-44.

Jung, P., Sato, T., Merlos-Suárez, A., Barriga, F. M., Iglesias, M., Rossell, D. Auer, H., Gallardo, M., Blasco, M. A., Sancho, E. et al. (2011). Isolation and in vitro expansion of human colonic stem cells. Nat. Med. 17, 1225-1227.

Korinek, V., Barker, N., Moerer, P., van Donselaar, E., Huls, G., Peters, P. J. and Clevers, H. (1998). Depletion of epithelial stem-cell compartments in the smal intestine of mice lacking Tcf-4. Nat. Genet. 19, 379-383.

Krejči, A., Bernard, F., Housden, B. E., Collins, S. and Bray, S. J. (2009). Direct response to Notch activation: signaling crosstalk and incoherent logic. Sci. Signal. 2, ra1.

Kwon, C., Cheng, P., King, I. N., Andersen, P., Shenje, L., Nigam, V. and Srivastava, D. (2011). Notch post-translationally regulates beta-catenin protein in stem and progenitor cells. Nat. Cell Biol. 13, 1244-1251.

Li, L. and Clevers, H. (2010). Coexistence of quiescent and active adult stem cells in mammals. Science 327, 542-545.

Marshman, E., Booth, C. and Potten, C. S. (2002). The intestinal epithelial stem cell. Bioessays 24, 91-98

Molofsky, A. V., He, S., Bydon, M., Morrison, S. J. and Pardal, R. (2005). Bmi-1 promotes neural stem cell self-renewal and neural development but not mouse growth and survival by repressing the p16Ink4a and p19Arf senescence pathways. Genes Dev. 19, 1432-1437.

Montgomery, R. K., Carlone, D. L., Richmond, C. A., Farilla, L., Kranendonk, M. E. G., Henderson, D. E., Baffour-Awuah, N. Y., Ambruzs, D. M., Fogli, L. K. Algra, S. et al. (2011). Mouse telomerase reverse transcriptase (mTert) expression marks slowly cycling intestinal stem cells. Proc. Natl. Acad. Sci. USA 108, 179-184

Muñoz, J., Stange, D. E., Schepers, A. G., van de Wetering, M., Koo, B.-K., Itzkovitz, S., Volckmann, R., Kung, K. S., Koster, J., Radulescu, S. et al. (2012). The Lgr5 intestinal stem cell signature: robust expression of proposed quiescent '+4' cell markers. EMBO J. 31, 3079-3091.

Oguro, H., Iwama, A., Morita, Y., Kamijo, T., van Lohuizen, M. and Nakauchi, H. (2006). Differential impact of Ink4a and Arf on hematopoietic stem cells and their bone marrow microenvironment in Bmi1-deficient mice. J. Exp. Med. 203 2247-2253.

Pan, M.-R., Peng, G., Hung, W.-C. and Lin, S.-Y. (2011). Monoubiquitination of $\mathrm{H} 2 \mathrm{AX}$ protein regulates DNA damage response signaling. J. Biol. Chem. 286 28599-28607.

Park, I.-K., Morrison, S. J. and Clarke, M. F. (2004). Bmi1, stem cells, and senescence regulation. J. Clin. Invest. 113, 175-179.

Pellegrinet, L., Rodilla, V., Liu, Z., Chen, S., Koch, U., Espinosa, L., Kaestner, K. H., Kopan, R., Lewis, J. and Radtke, F. (2011). DIl1- and dll4-mediated notch signaling are required for homeostasis of intestinal stem cells. Gastroenterology 140, 1230-1240. e1231-1237.

Potten, C. S., Owen, G. and Booth, D. (2002). Intestinal stem cells protect their genome by selective segregation of template DNA strands. J. Cell Sci. 115, 2381-2388.

Riccio, O., van Gijn, M. E., Bezdek, A. C., Pellegrinet, L., van Es, J. H., ZimberStrobl, U., Strobl, L. J., Honjo, T., Clevers, H. and Radtke, F. (2008). Loss of intestinal crypt progenitor cells owing to inactivation of both Notch1 and Notch2 is accompanied by derepression of CDK inhibitors p27Kip1 and p57Kip2. EMBO Rep. 9, 377-383.

Rodilla, V., Villanueva, A., Obrador-Hevia, A., Robert-Moreno, A., FernandezMajada, V., Grilli, A., Lopez-Bigas, N., Bellora, N., Alba, M. M., Torres, F. et al. (2009). Jagged1 is the pathological link between Wnt and Notch pathways in colorectal cancer. Proc. Natl. Acad. Sci. USA 106, 6315-6320.

Roman, A. C., Benitez, D. A., Carvajal-Gonzalez, J. M. and Fernandez-Salguero, P. M. (2008). Genome-wide B1 retrotransposon binds the transcription factors dioxin receptor and Slug and regulates gene expression in vivo. Proc. Natl. Acad. Sci. USA 105, 1632-1637.

Sangiorgi, E. and Capecchi, M. R. (2008). Bmi1 is expressed in vivo in intestinal stem cells. Nat. Genet. 40, 915-920.

Sato, T., Vries, R. G., Snippert, H. J., van de Wetering, M., Barker, N., Stange, D. E., van Es, J. H., Abo, A., Kujala, P., Peters, P. J. et al. (2009). Single Lgr5 stem cells build crypt-villus structures in vitro without a mesenchymal niche. Nature 459, 262-265.

Sato, T., van Es, J. H., Snippert, H. J., Stange, D. E., Vries, R. G., van den Born, M., Barker, N., Shroyer, N. F., van de Wetering, M. and Clevers, H. (2011). Paneth cells constitute the niche for Lgr5 stem cells in intestinal crypts. Nature 469, 415-418.

Schepers, A. G., Vries, R., van den Born, M., van de Wetering, M. and Clevers, H. (2011). Lgr5 intestinal stem cells have high telomerase activity and randomly segregate their chromosomes. EMBO J. 30, 1104-1109.

Takeda, N., Jain, R., LeBoeuf, M. R., Wang, Q., Lu, M. M. and Epstein, J. A. (2011). Interconversion between intestinal stem cell populations in distinct niches. Science 334, 1420-1424.

Tian, H., Biehs, B., Warming, S., Leong, K. G., Rangell, L., Klein, O. D. and de Sauvage, F. J. (2011). A reserve stem cell population in small intestine renders Lgr5-positive cells dispensable. Nature 478, 255-259.

Ueo, T., Imayoshi, I., Kobayashi, T., Ohtsuka, T., Seno, H., Nakase, H., Chiba, T. and Kageyama, R. (2012). The role of Hes genes in intestinal development, homeostasis and tumor formation. Development 139, 1071-1082.

van de Wetering, M., Sancho, E., Verweij, C., de Lau, W., Oving, I., Hurlstone, A van der Horn, K., Batlle, E., Coudreuse, D., Haramis, A.-P. et al. (2002). The beta-catenin/TCF-4 complex imposes a crypt progenitor phenotype on colorecta cancer cells. Cell 111, 241-250.

van der Flier, L. G., van Gijn, M. E., Hatzis, P., Kujala, P., Haegebarth, A., Stange, D. E., Begthel, H., van den Born, M., Guryev, V., Oving, I. et al. (2009). Transcription factor achaete scute-like 2 controls intestinal stem cell fate. Cell 136 903-912.

van Es, J. H., van Gijn, M. E., Riccio, O., van den Born, M., Vooijs, M., Begthel, H., Cozijnsen, M., Robine, S., Winton, D. J., Radtke, F. et al. (2005). Notch gamma-secretase inhibition turns proliferative cells in intestinal crypts and adenomas into goblet cells. Nature 435, 959-963.

Yan, K. S., Chia, L. A., Li, X., Ootani, A., Su, J., Lee, J. Y., Su, N., Luo, Y., Heilshorn, S. C., Amieva, M. R. et al. (2012). The intestinal stem cell markers Bmi1 and Lgr5 identify two functionally distinct populations. Proc. Natl. Acad. Sci. USA 109, 466-471.

Yin, X., Farin, H. F., van Es, J. H., Clevers, H., Langer, R. and Karp, J. M. (2014) Niche-independent high-purity cultures of Lgr5+ intestinal stem cells and their progeny. Nat. Methods 11, 106-112.

Yu, T., Chen, X., Zhang, W., Colon, D., Shi, J., Napier, D., Rychahou, P., Lu, W. Lee, E. Y., Weiss, H. L. et al. (2012). Regulation of the potential marker for intestinal cells, Bmi1, by beta-catenin and the zinc finger protein KLF4 implications for colon cancer. J. Biol. Chem. 287, 3760-3768.

Zacharek, S. J., Fillmore, C. M., Lau, A. N., Gludish, D. W., Chou, A., Ho, J. W. K. Zamponi, R., Gazit, R., Bock, C., Jäger, N. et al. (2011). Lung stem cell selfrenewal relies on BMI1-dependent control of expression at imprinted loci. Cell Stem Cell 9, 272-281. 


\section{Supplementary Figures}

Figure S1. Expression of active $\beta$-catenin in response to tamoxifen treatment.

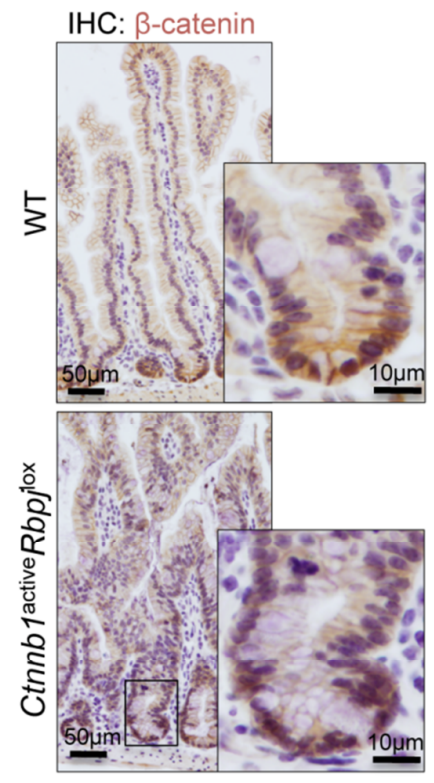

Figure S1: Active $\beta$-catenin expression in the intestinal cells detected by $\mathrm{IHC}, 4$ days after tamoxifen treatment. Ctnnb $1^{\text {active }}$ corresponds to the $\beta$-catenin GOF mutant $C$ tnnb $1^{\text {10x(ex3) }}$ and $R b p j^{\text {jox }}$ to the Notch LOF mutant. 
Figure S2: Notch and Wnt/ $\beta$-catenin co-regulate gene expression.

A

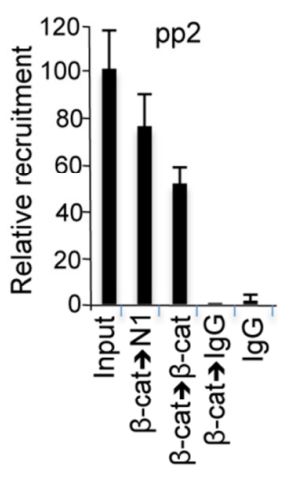

C

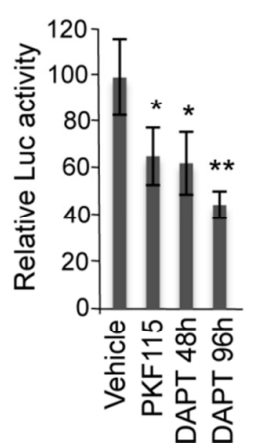

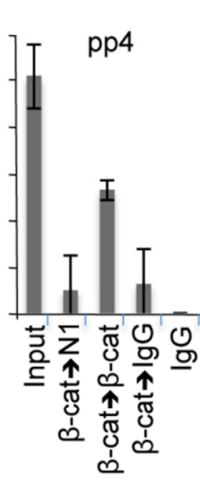

$\mathrm{D}$

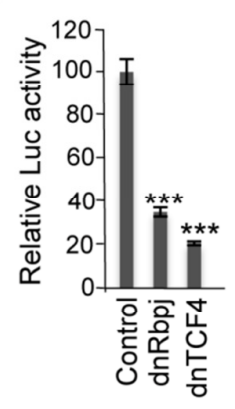

B

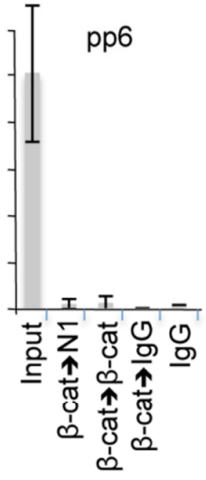

$\mathrm{E}$

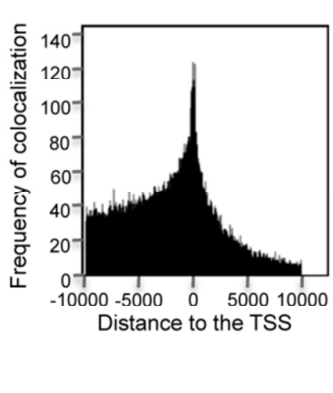

$\mathrm{hBmi1}$ promoter $(2.5 \mathrm{kB})$

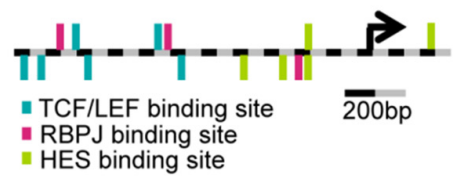

$\mathrm{F}$

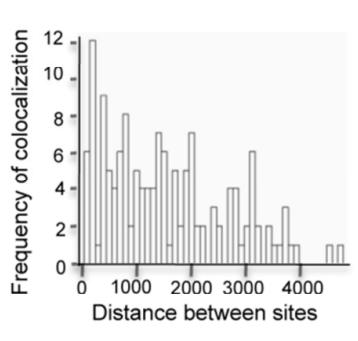

Figure S2 (A) Quantitative analysis of $\beta$-catenin and $\beta$-catenin/Notch1 co-recruitment to the Bmi1 promoter region as determined by q-PCR analysis with the indicated primer pairs (see details in Figure 2B). Average and standard deviation values obtained from two independent ChIP experiments are shown. (B) Scheme of the 2-kb proximal promoter of the indicated genes showing the position of RBPJ- and TCF4-binding sites and TSS. Red boxes represent RBPJ-binding sites and green boxes, TCF4-binding sites predicted with Genomatix Software. (C-D) Bmi1 reporter assay to test the effect of pharmacological inhibitors (C) or the indicated constructs (D). (E-F) Bioinformatic analysis of the whole human genome sequence demonstrating that TCF and RBPJ binding consensus colocalized close to the TSS of the gene promoters $(E)$ and determine the presence of adjacent consensus sequences $(F)$. 
Figure S3. Knockout phenotype is detected from the stage of villogenesis and results in intestinal defects at birth.

A

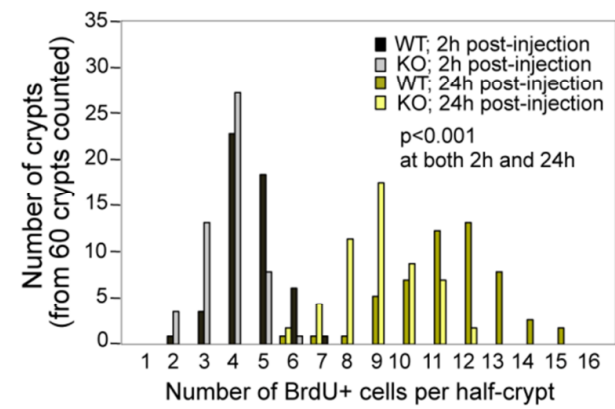

C
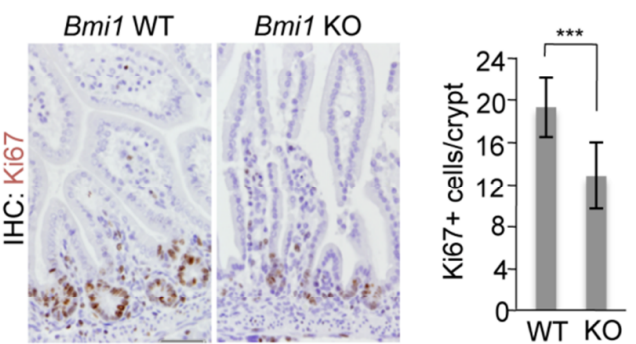

E

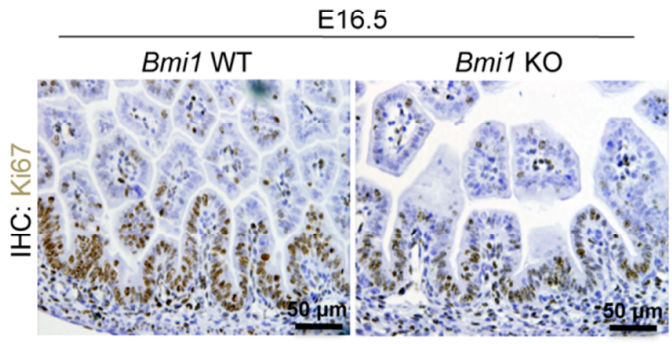

B
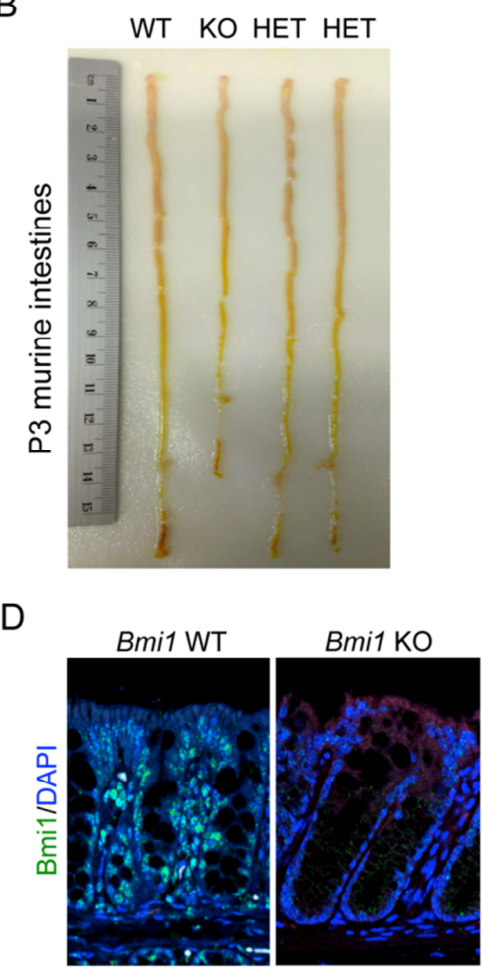

Figure S3: (A) Quantification of the number of crypts with the indicated number of BrdU positive cells in the WT and KO Bmi1 animals at $2 \mathrm{~h}$ or $24 \mathrm{~h}$ after injection. (B-C) Stereoscopical image (B) and (C) IHC of Ki67 in the intestine of the indicated Bmi1 genotypes (WT: wildtype; KO: knockout; HET: heterozygous) collected at day 3 of age (P3). Quantification of the number of Ki67+ cells per crypt is shown in the right panel. (D) Bmi1 protein expression in the mouse colonic mucosa. One section of a Bmi1 deficient colonic mucosa was processed in parallel and is shown as a negative control. (E) Ki67 staining of Bmi1 WT and KO intestines at day E16.5 of development. 
Figure S4. Notch and Bmi1 are active in the ISC and their suppression results in ISC loss in vitro.

A

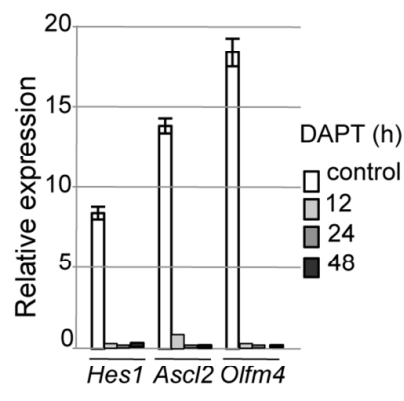

B

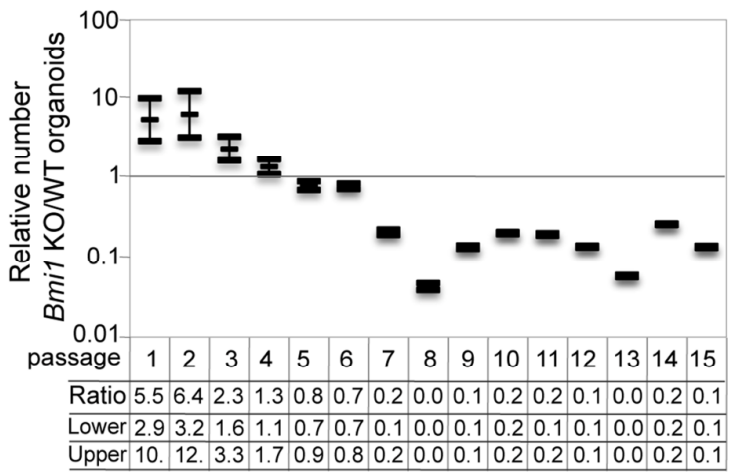

Figure S4: (A) q-RT-PCR to measure the expression levels of the indicated genes in organoid cultures treated with the Notch inhibitor DAPT. (B) Quantification of the average number of organoids obtained from Bmi1 KO and Bmi1 WT crypt cells. The ratio between the average number of $\mathrm{KO}$ and WT organoids obtained at the different passages (from a minimum of 3 wells counted) is represented. Note the inverted ratio after passage 7. 
Table S1. Related to Experimental Procedures. (A) Primer sequence of different genes used by expression analysis. (B) Primer sequence of different genes used by Chromatin immuno-precipitation assays.

TABLE S1A | qRT-PCR primers

\begin{tabular}{|c|c|c|}
\hline Murine Gene & Sense primer $5^{\prime}-3^{\prime}$ & Antisense primer 5'-3' \\
\hline Villin & CACCTTTGGAAGCTTCTTCG & CTCTCGTTGCCTTGAACCTC \\
\hline Gapdh & TGTTCCTACCCCСAATGTGT & TGTGAGGGAGATGCTCAGTG \\
\hline$\beta 2$ microglobulin & CTGACCGGCCTGTATGCTAT & CAGTCTCAGTGGGGGTGAAT \\
\hline Lgr5 & CGTCTTGCTGGAAATGCTTTGAC & AAGGCGTAGTCTGCTATGTGGTG \\
\hline Olfm4 & GCTGGAAGTGAAGGAGATGC & ACAGAAGGAGCGCTGATGTT \\
\hline Ascl2 & AGCATGGAAGCACACCTTG & AAGTGGACGTTTGCACCTTC \\
\hline Bmi1 & CCAATGAAGACCGAGGAGAA & TTTCCGATCCAATCTGCTCT \\
\hline EphB2 & TTCTCACCTCAGTTCGCCTCTG & CAAACCCCCGTCTGTTACATACG \\
\hline сMус & TATCACCAGCAACAGCAGAGCGAG & AACATAGGATGGAGAGCAGAGCCC \\
\hline p16Ink4a & GTCGTACCCCGATTCAGGT & ACCAGCGTGTCCAGGAAG \\
\hline p19Arf & CATGTTGTTGAGGCTAGAGAGG & ACCAGCGTGTCCAGGAAG \\
\hline Hopx & GAGGACCAGGTGGAGATCCT & TCCGTAACAGATCTGCATTCC \\
\hline Lrig1 & CCAAAAGCTGCATGAGTTGA & GCACCACTGGTATCCTCGAT \\
\hline mTert & AGGGTAAGCTGGTGGAGGTT & GATGCTCTGCTCGATGACAA \\
\hline Hes1 & CGGCATTCCAAGCTAGAGAAGG & GGTAGGTCATGGCGTTGATCTG \\
\hline Lyz1 & AGACCGAAGCACCGACTATG & CGGTTTTGACATTGTGTTCG \\
\hline Muc5 & AATCAGATGGGCTGTGTTCC & TCAGCACATAGGTGCAGTCC \\
\hline Human Gene & Sense primer $5^{\prime}-3^{\prime}$ & Antisense primer $5^{\prime}-3^{\prime}$ \\
\hline$\beta$-ACTIN & CGC AAGTACTCCGTGTGGA & CGGCCACATTGTGAACTTTG \\
\hline$B M / 1$ & CACCAGAGAGATGGACTGACAAATG & TGAGGAAACTGTGGATGAGGAGAC \\
\hline$C-M Y C$ & CGTGGTATGTATGGGAGATGGCAG & GGACAGTAGGAAAGGAAGTGGGATG \\
\hline EPHB2 & CCAGACAAGCATCCAGGAGAAGTTG & AGATTGGGGAACCGACAGTGAAGG \\
\hline EREG & CTGCCTGGGTTTCCATCTTCTAC & TGTTATTGACACTTGAGCCACACG \\
\hline AMOTL2 & AGCAGGTTAAAGGTGCTCCA & TCTGCTGTTTGTCGCTCACT \\
\hline HES1 & AAATGACAGTGAAGCACCTCCG & GAAGCCTCCAAACACCTTAGCC \\
\hline
\end{tabular}

TABLE S1B | ChIP primers

\begin{tabular}{lll}
\hline Human Gene & Sense primer 5'-3' & Antisense primer 5'-3' \\
\hline BMI1-PRO1 & TAGAGCCAACTCCACGTTCC & CGCTGGAGTGATCATAGCAA \\
BMI1-PRO2 & TGGCTTTGAAATGTCTTTGC & TCTGCAGAAGATGCCTTTGA \\
BMI1-PRO3 & GGCATCTTCTGCAGAGTCGT & CGGTTATTTGCCCTCACACT \\
C-MYC-PRO1 & TGGATGCATTCATTTCCTGA & GTGTGGGAGCCTCTGCTAAG \\
C-MYC-PRO2 & CCTCCCATATCTCCCGTCT & TGTGTCTGCCTGTTCCAGAG \\
C-MYC-PRO3 & GCGCCCATTAATACCCTTCT & CAGCCGAGCACTCTAGCTCT \\
EPHB2-PRO1 & CGTTGGTGGGACTGAAAACT & GTGAGAACATGCGGTGTTTG \\
EPHB2-PRO2 & TGAATCCTAGCCCAATTTGC & AGGGCCAGTGGTTACTTCCT \\
EPHB2-PRO3 & AAGGCCCAGTCTCCCACT & TACCTGTCAGGGCAGGGAGT
\end{tabular}

